\title{
Public sexual health promotion interventions and strategies: A qualitative study
}

\author{
Zahra Bostani Khalesi ${ }^{1}$, Masoumeh Simbar $^{2}$, Seyed Ali Azin ${ }^{3}$, Farid Zayeri ${ }^{4}$
}

${ }^{1}$ Ph.D. Candidate of Reproductive Health, Student Research Office, School of Nursing \& Midwifery, Shahid Beheshti University of Medical Sciences, Tehran, Iran

${ }^{2} \mathrm{Ph} . \mathrm{D}$. of Reproductive Health, Professor, Department of Midwifery \& Reproductive Health, School of Nursing \& Midwifery, Reproductive Endocrinology Research Center, Research Institute for Endocrine Sciences, Shahid Beheshti University of Medical Science, Tehran, Iran

${ }^{3}$ MD, Specialist in Social Medicine, Reproductive Biotechnology Research Center, Avicenna Research Institute (ACECR), Tehran, Iran

${ }^{4}$ Ph.D. of Statistics, Associate Professor, Department of Biostatistics, Shahid Beheshti University of Medical Sciences, Tehran Iran

\section{Type of article: Original}

\begin{abstract}
Introduction: Sexual health promotion is the process of enabling people to increase control over their sexual health that should be based on people's needs and abilities. The aim of this study was to explore public sexual health promotion interventions and strategies.

Methods: This study was a qualitative content analysis approach. This qualitative study was a qualitative part of an exploratory sequential qualitative-quantitative study that took place between November 2014 and May 2015 and was conducted in Rasht, Iran. Data were collected using semi-structured interviews with 38 engaged and married men and women as well as nine key informants. The data were analyzed by the content analysis method and by using qualitative data analysis software MAXqda 2011.

Results: Analyzing participants' perspectives and experiences revealed two main categories, i.e., 1) General actions to promote sexual health (with three sub-categories: public policies promoting sexual health, development of sexual health supporting environments, and removal of barriers to receiving services) and 2) Specific actions in the current health system (with three sub-categories: economic policy, empowering individuals and the society, and reviewing the current health system).

Conclusions: General actions (public policies, supporting environments developed, and removal of barriers to receiving services) and integration of specific actions in the health system, such as empowering individuals' needs for promoting sexual health. Achieving these goals necessitates the review of the current health system in Iran.

Keywords: Sexual health; Health promotion; Qualitative study; Iran
\end{abstract}

\section{Introduction}

Benefiting from good health is the right of everyone. Sexual health is a vital and integral part of your overall health and well-being throughout your life and is not just the absence of disease or dysfunction (1). It is an important part of physical and emotional health that requires a positive approach to sexuality and sexual relationships, as well as the possibility of having enjoyable and harmless sexual experiences, freedom from fear, shame, guilt, false beliefs, and other psychological factors that inhibit sexual response and impair sexual relationships (2). Sexual health promotion is the process by which individuals achieve the ability to control and improve their sexual health (3). The

\section{Corresponding author:}

Professor Dr. Masoumeh Simbar, Department of Midwifery \& Reproductive Health, School of Nursing \& Midwifery, Reproductive Endocrinology Research Center, Research Institute for Endocrine Sciences, Shahid Beheshti University of Medical Science, Tehran, Iran.

Tel: +98.4133860716, Fax:+98.4133297101, E-mail: msimbar@yahoo.com

Received: January 08, 2016, Accepted: April 23, 2016, Published: June 2016

iThenticate screening: April 21, 2016, English editing: May 17, 2016, Quality control: June 04, 2016

(C) 2016 The Authors. This is an open access article under the terms of the Creative Commons Attribution-NonCommercialNoDerivs License, which permits use and distribution in any medium, provided the original work is properly cited, the use is non-commercial and no modifications or adaptations are made. 
promotion of sexual health should enhance sexual and emotional well-being and help people to reduce the risk of sexually-transmitted diseases (STDs), HIV, and unwanted pregnancies (4). Strategies to promote sexual health focus on changing people's behaviors through a series of educational, motivational, peer-group, and skills-building approaches (5). Sexual health interventions are complex interventions with the aim of enhancing sexual well-being and reducing STDs and unwanted pregnancies (6). Individuals cannot achieve their maximum sexual health capacity until they have control over these components (7). Promoting positive sexual health and well-being involves education to develop the capacity of people to understand their sexuality in the context of biological, psychological, and sociocultural considerations and to acquire skills in managing responsible decisions and actions with regard to sexual health behavior $(8,9)$. More than a decade ago, sexual health clinics were established in Iran to respond to couples' concerns and questions about sexual problems and to prevent and treat sexually transmitted infections; it also provides people with counseling and education related to sexual issues $(10,11)$. But there is a great gap in the delivery of sexual health services for the Iranian people, especially the young people, and this gap includes the lack of formal education, invalid resources of sexual information, socio-cultural changes (12), and challenges in providing sexual health services. Unfortunately, most families do not receive sufficient sexual education because they don't know about sexual health clinics or they feel embarrassed to go to such centers because of the cultural sensitivity and taboos (13). Thus, to deal with these threatening factors, it is essential to utilize sexual health promoting interventions in order to enlighten individuals, correct their attitudes, prevent and treat the related diseases, and involve target groups in sexual health promotion interventions (14), So, for the first time, we conducted a qualitative study in Iran with the aim of exploring sexual health promotion interventions by obtaining the perspectives and experiences of engaged and married men, women, and key informants.

\section{Material and Methods}

\subsection{Study design}

This study was a qualitative content analysis approach. This qualitative study was a qualitative part of an exploratory sequential qualitative-quantitative study that took place between November 2014 and May 2015 and was conducted in Rasht, Iran.

\subsection{Setting and participants}

The studied sample consisted of 38 engaged and married men and women and nine key informants. These samples were selected using the purposeful sampling method with maximum variation sampling. The participants were engaged men and women who had been referred to health centers to get pre-marriage counseling classes and married men and women to get primary health care with maximum variety of factors, such as age, education, socioeconomic status, and place of residence (urban and rural). The inclusion criteria were fluency in the Persian language, engaged or married, no chronic diseases or mental illnesses, and agreeing to participate in the study.

\subsection{Data Collection}

Data collection was conducted using semi-structured, in depth interviews. Because of the depth and flexibility in qualitative studies, semi-structured interviews were used for data collection. The interview guide contained elementary questions and was developed by researchers, and its validity was confirmed by the expert researchers in the field of sexual health. In order to protect the rights of the participants, the research team explained the purpose of the study, assured participants that their information would be private and confidential, and explained that participants could withdraw from the study at any time. All participants who participated in the study signed written informed consent forms. The volunteers were taken to a private room (in the health center provider's pre-marriage counseling room in Rasht) for a full explanation of the project, and, if the participant agreed and completed the consent form, the interview began. Data collectors were placed in two male-female groups. The male interviewer was allocated to male participants, and the female interviewer was assigned to the female participants. The interviews were conducted face-to-face and in the appropriate places. The interviews began with a general question, i.e., "Could you please talk about your understanding about the concept of sexual health?" The major focus of the questions was "What do you recommend for improving people's sexual issues?", and the participants were asked to express their opinions, experiences, and views. The next questions were asked based on the participants' experiences in order to achieve additional information about sexual health promotion interventions. The interviews were recorded using a digital voice recorder (Sony ICD PX333 Digital Voice Recorder). Each interview lasted between 45 and 60 minutes. Data collection was continued until data saturation was reached, i.e., the new data entered into the study did not create new themes or change the existing themes. After each interview, it was transcribed immediately verbatim. For immersion in the data, the interview transcription was reviewed several times. 


\subsection{Data Analysis}

The Graneheim and Lundman approach was used in the conventional content analysis. The analysis began with transcribing all the interviews and then determining the analysis unit, the meaning unit, summarizing the meaning units, determining primary codes, categorizing similar primary codes in more comprehensive categories, and determining themes (15). First, the interviews were transcribed verbatim and typed immediately after each interview. To detect the meaning unit, each interview was read and reviewed. All words, sentences, and paragraphs that included the most important points regarding the sexual health promotion interventions determined as the meaning unit. Then, the meaning units were reviewed several times and were coded based on the conceptual and meaning units. After extracting the original codes, similar codes were integrated and categorized based on their similarities. The categories and subcategories were compared, and the themes were determined by analyzing and interpreting these categories and subcategories. MAXqda 2011 software was used to classify the transcribed data.

\subsection{Trustworthiness of data}

In this study, we used the Lincoln and Guba (1989) criteria to ensure rigor and trustworthiness. The criteria included credibility, dependability, confirmability, and transferability (16). The credibility of data was enhanced by using member check, long engagement with the participants, and data immersion, using participants' opinions to confirm the extracted codes and categories, and having maximum variation sampling in terms of age, education, occupation, and location (rural /urban). Transferability of data was determined by reviewing the findings by the participants who met the inclusion criteria but did not participate in the research, and they confirmed the fitness of the results. For enhancing the dependability, the extracted codes and categories were reviewed by two researchers who were experts in qualitative research and who supervised all of the research phases. To improve the confirmability of the findings, the views of experienced researchers in the field of sexual health, who were not on the research team, were used at all stages of the process, such as data sampling, collection, analysis, and interpretation.

\subsection{Ethical considerations}

The Ethics Committee at Shahid Beheshti University of Medical Sciences approved the study (Approval No. SBMU2.REC.1394.130). The participants were informed that they could discontinue the interviews at any time for any reason. The interviews were stopped based on participants' willingness and emotional situation and continued when they felt it appropriate to do so. All of the interviews were performed in a private room ensure the confidentiality of the information that was provided.

\section{Results}

\subsection{Demographic characteristics}

The study participants consisted of 23 women between the ages of 17 and 46 and 15 men between the ages of 23 and 35. The participants' characteristics are presented in Table 1.

Table 1. Demographic characteristics of participants in the in-depth interviews

\begin{tabular}{|l|l|l|l|l|}
\hline Variable/ Gender & Male $(\mathrm{n}=15)$ & Female $(\mathrm{n}=23)$ & Total $(\mathrm{n}=38)$ \\
\hline Mean age (years) & & 31.3 & 28.6 & 33.8 \\
\hline Education & $\begin{array}{l}\text { Primary or Secondary } \\
\text { School Education }\end{array}$ & $2(13.3)$ & $1(4.3)$ & $3(7.9)$ \\
\cline { 2 - 5 } & High School & $1(6.7)$ & $3(13)$ & $4(10.5)$ \\
\cline { 2 - 5 } & High School Diploma & $4(26.7)$ & $9(39.2)$ & $13(34.2)$ \\
\cline { 2 - 5 } & Above & $8(53.3)$ & $10(43.5)$ & $18(47.3)$ \\
\hline \multirow{5}{*}{ Employment status } & Householder or Unemployed & $2(13.3)$ & $15(65.2)$ & $17(44.7)$ \\
\cline { 2 - 5 } & Government Employee & $8(53.3)$ & $7(30.5)$ & $15(39.5)$ \\
\cline { 2 - 5 } & Self Employed & $5(33.3)$ & $1(4.3)$ & $6(15.7)$ \\
\hline \multirow{2}{*}{ Marital status } & Single & $10(66.7)$ & $16(65.5)$ & $26(68.4)$ \\
\cline { 2 - 5 } & Married & $5(33.3)$ & $7(30.5)$ & $12(31.5)$ \\
\hline Residency & Urban & $9(4.3)$ & $15(65.2)$ & $24(63.2)$ \\
\cline { 2 - 5 } & Rural & $6(40)$ & $8(34.8)$ & $14(36.8)$ \\
\hline
\end{tabular}

In this study, the key informants were health education specialists, psychologists, psychiatrists, premarital classes' educators, and clergymen. The demographic characteristics of the key informants are shown in Table 2. Analyzing 
participants' perspectives and experiences revealed that the definition of sexual health from the view of participants was having sexual intercourse without the risk of contracting sexually-transmitted disease. After data analysis, two main categories and 6 sub-categories were extracted, and they are presented in Table 3.

Table 2. Demographic characteristics of key informants

\begin{tabular}{|l|l|l|l|}
\hline Gender & Age & Field of Study/Academic Degree & Occupation \\
\hline Female & 48 & Health education (Ph.D.) & Faculty member \\
\hline Woman & 33 & Health education (Ph.D.) & Faculty member \\
\hline Woman & 43 & Midwifery (Bachelor) & Premarital Preparation Course Provider \\
\hline Male & 53 & Psychiatrist (Clinician) & Private sector \\
\hline Man & 53 & Psychologist (Ph.D.) & Private sector \\
\hline Man & 64 & Psychologist (Ph.D.) & Private sector \\
\hline Man & 48 & Psychologist (Ph.D.) & Faculty member \\
\hline Man & 61 & Philosophy and Islamic theology (Level 3) & Clergyman-Faculty member \\
\hline Man & 58 & Koran and Hadith Sciences (Level 2) & Clergyman \\
\hline
\end{tabular}

Table 3. Main categories, sub- categories, and codes in this study

\begin{tabular}{|c|c|c|}
\hline Main categories & Sub-categories & Codes \\
\hline \multirow{8}{*}{$\begin{array}{l}\text { General actions to } \\
\text { promote sexual health }\end{array}$} & \multirow{3}{*}{$\begin{array}{l}\text { Public policies promoting sexual } \\
\text { health }\end{array}$} & Increasing access to counseling services \\
\hline & & Gaining the support of policy-makers \\
\hline & & Taking legal actions against sexual abuse \\
\hline & \multirow[t]{3}{*}{$\begin{array}{l}\text { Development of sexual health } \\
\text { supporting environments }\end{array}$} & $\begin{array}{l}\text { Development of religious and cultural } \\
\text { environments }\end{array}$ \\
\hline & & $\begin{array}{l}\text { Development of governmental centers presenting } \\
\text { sexual health services }\end{array}$ \\
\hline & & $\begin{array}{l}\text { Involving the target group in all the steps of } \\
\text { planning, implementation, and evaluation }\end{array}$ \\
\hline & \multirow{2}{*}{$\begin{array}{l}\text { Removing barriers to receiving } \\
\text { services }\end{array}$} & Stigma \\
\hline & & Taboo, social sanctions \\
\hline \multirow{8}{*}{$\begin{array}{l}\text { Specific actions in the } \\
\text { current health system }\end{array}$} & \multirow[t]{4}{*}{ Economic policy } & Heavy costs \\
\hline & & Allocation of resources \\
\hline & & Financially supporting private sectors \\
\hline & & Insurance support of counseling services \\
\hline & \multirow[t]{2}{*}{$\begin{array}{l}\text { Empowering people and the } \\
\text { society }\end{array}$} & $\begin{array}{l}\text { Prioritizing sexual health in health related policy- } \\
\text { making }\end{array}$ \\
\hline & & Training experts \\
\hline & \multirow[t]{2}{*}{$\begin{array}{l}\text { Reviewing the current system of } \\
\text { services }\end{array}$} & $\begin{array}{l}\text { Integration of sexual health in primary health } \\
\text { care program }\end{array}$ \\
\hline & & Sexual health system design \\
\hline
\end{tabular}

\subsection{General actions to promote sexual health}

The first inferred concept was general actions to promote sexual health, which was formed from the three concepts of "public policies promoting sexual health," "development of sexual health supporting environments," and "removal of barriers to receiving sex-related services,"

\subsubsection{Public policies promoting sexual health}

Some of the participants believed that increased access to counseling services could improve the sexual health level and decrease irreparable damage. In this regard, one participant said: "Currently, the most important measure is availability and access to counseling services. Because, I think that increased access to sexual health services could decrease a lot of irreparable damage, such as AIDS. In addition, sexual health counseling services will improve the sexual health level of society through awareness raising" (a 33-year-old woman, Ph.D. in Health Education). Gaining the support of policy-makers was another strategy discussed by the participants. One of the participants said: " To get comprehensive sexual health education must be planned and for long-term planning and is needed policy-makers' support"(a 53-year-old man, Psychiatrist). Based on the experiences of the participants, taking legal actions against sexual abuse could diminish sexual harassment and its consequences. One of the participants said: "I know someone who has deliberately chosen to be a school shuttle driver for little girls to be able to sexual abuse. 
These are some mentally ill patients that should be stopped ... The long punishments behind bars do help many" (a 25-year-old man, high school diploma, self-employed).

\subsubsection{Development of environments that support sexual health}

More than half of the participants regarded the development of religious and cultural spaces as the essential components to deal with western culture and media invasion. One of the participants pointed out: "When we deprive our teenagers or youth of watching many things, they should be instead encouraged to see informative programs which could contribute to them in terms of value and deepen their faith ... We should improve cultural programs of mosques and arrange cultural-educational camps" (a 23-year-old man, Students). Almost all of the participants believed that the development of governmental centers to provide sexual health services could be a very effective intervention for improving sexual health. One of the participants said: "There should be a large number of governmental centers for providing free counseling, and even health, services" (a 43-year-old woman, Bachelor of Midwifery, Premarital Preparation Course Provider). Some participants stated that the involvement of the target group in all the steps of planning, implementation, and evaluation of services could play an important role in promoting their sexual health. One participant said: "To succeed in every educational process, the target group should be involved in the planning, implementation and evaluation stages from beginning to the end" (a 33 -year-old woman, Ph.D. in Health Education).

\subsubsection{Removing barriers to receiving services}

Some participants believed that stigma could prevent people from being referred to sexual health clinics for receiving services and lead to high-risk behaviors. One of the participants said: "Health centers can be very useful; but, it should not be a specific center that anyone went there, be stigmatized, and all understand Went there for what " (a 27-year-old woman, high school diploma householder). Most participants considered embarrassment and stigma as major obstacles to getting sexual health services. In this regard, one of the participants said: "Embarrassment and stigma are major barriers to the use of sexual health services. Many people will be embarrassed to talk about their sexual problems, but if sexual health services offered by the health center, this problem will be solved to some extent, because no one knows what they came here for!" (a 43-year-old woman, Bachelor of Midwifery, Premarital educator).

\subsubsection{Specific actions in the current health system}

The second concept was "Specific actions in the current health system." Most of the participants believed that economic policy, empowering individuals, and the society and reviewing the current health system would be effective strategies for sexual health promotion.

\subsubsection{Economic policy}

All the participants talked about the heavy costs of counseling services and some pointed out this reason as their lack of referral to counseling centers. One of the participants said: "Counseling costs are too high; only some high-class people can afford them" (a 27-year-old woman, English language student). A large number of participants regarded the allocation of resources as an important factor to promote sexual health. One of the participants said: "A separate budget should be allocated for this goal (sexual health) "(a 32-year-old man, associate degree in electronics, worker). Some of the participants pointed to the importance of financial support for the private sector. One of them said: "The government's support of the private sector is certainly helpful" (a 48-year-old man, Clinical psychologist). A large number of participants emphasized the insurance support of counseling services. One of them stated: "Gaining access to free services helps prevent most of the secret searches on the Internet" (a 33-year-old man, Ph.D. in Chemistry, university lecturer).

\subsubsection{Empowering people and society}

Prioritizing sexual health in policy-making was one of the points expressed by the participants. One participant said: "Sexual health should be the priority for those who are responsible for policy- and decision-making on health; all other organizations should also have sufficient cooperation" (a 33-year-old woman, Ph.D. in Health Education). Some participants believed that it is essential to train experts in promoting sexual health. One of the participants said: "We have a very low number of sexual health specialists in Iran, and specialists in this field should be trained to a sufficient number, to achieve this goal, we need macro-level planning, investment, human resources, and expertise" (a 53-year-old man, Psychiatrist).

\subsubsection{Reviewing current health system}

Some participants considered the integration of sexual health in primary health care program an effective strategy for improving sexual health. One of the participants said: "To succeed in sexual health programs, the sexual health services should be integrated into primary health care "(a 48-year-old woman, Ph.D. in Health Education). Designing a sexual health system was among the points emphasized by many participants. One of the participants said: "They should make people aware about using only reliable websites. For example, the Ministry of Health can 
build a website for sexual health education; then, ordinary people can safely use it" (a 32-year-old man, Master of electronics, employee).

\section{Discussion}

The majority of the participants in this study considered the increased access to services a strategy for improving sexual health. In the study of Kirby et al. of people suffering from sexually-transmitted diseases, the most important priority in receiving sexual health services was reported to be access to services (17). From the perspective of the participants, gaining the support of policy-makers is necessary for promoting sexual health. The results of Harries et al.'s work showed that gaining policy-makers' support had a significant effect on the success of HIV prevention and treatment programs (18). In this study, most of the participants stated that taking legal actions against sexual abuse and its consequences could contribute to sexual health promotion. Participants' perceptions of sexual abuse were forcing undesired sexual intercourse and an act of physical violence, such as rape. Sexual abuse is associated with two consequences of uncontrollability and frigidity, and risky sexual behaviors are more observed among the people who have been sexually abused. Early detection and legal actions of responsible organizations can be useful for reducing the incidence of sexual abuse and its consequences (19). Some participants believed that the development of religious and cultural places is very essential for promoting sexual health. In this regard, the findings of Sobhanifar's study showed that, to confront the soft war and cultural invasion, cultural tools should be used and cultural products should be developed (20). Almost all of the participants believed that the development of governmental health centers would be a very effective strategy for sexual health promotion. In their study, Rogstad et al. concluded that, in addition to the observance of the standards of sexual health services, the quantitative development of centers providing these services is required for improving sexual health (21). The participants considered the involvement of target groups in all steps of planning, implementation, and evaluation of services as an essential and integral part for sexual health promotion programs. Involving individuals in the planning, implementation, and evaluation phases of health programs could improve health indices (22). Some participants believed that stigma prevents individuals from being referred to sexual health clinics to get their services and causes high-risk behaviors. Stigma and discrimination are the main obstacles that deprive HIV patients of their individual and social rights (23).

Taboos or social sanctions were mentioned as one of the barriers of sexual health services by the majority of the participants. In Iran, the taboos associated with sexual issues have deprived the youth of consulting with experts and getting the relevant necessary knowledge (12). Some of the participants noted heavy cost as another deterrent to getting sexual health services. The heavy costs of counseling and some health care costs not covered by insurance companies reduce the motivation of people for problem-solving (24). The majority of the participants emphasized the allocation of resources as an effective means of empowering people in the field of sexual health. Fair allocation of resources is one of the major challenges of every health system and the main part of the decision-making process that could be an obstacle to the implementation of comprehensive empowerment programs in the field of health (25). Some other participants highlighted the important role of supporting the private sector as a factor empowering people and the society in the field of sexual health. Private centers providing health services through training and counseling play an important role in promoting sexual health (26). Some participants believed that training expert forces is essential for promoting sexual health. Rahmanian et al. mentioned training of health service providers and considered training expert forces a requisite for the development of the health sector (27). Some of the participants expressed that the integration of sexual health in primary health care program can be effective in improving sexual health. In their study in Iran, Rostamkhani et al. (28) showed that using the Permission Limited Information Specific Suggestions Intensive Therapy (PLISSIT) model, sexual dysfunction, and sexual health needs of clients can be easily treated by the staff of health centers. In many cases, the participants said that the integration of sexual health in the school curricula can be very effective. In their study, Shahhosseini et al. demonstrated that the cooperation of civil institutions, such as schools, is essential for the effectiveness of sexual health education programs (29). A large number of participants emphasized the support of counseling services by insurance companies. The protection provided by insurance for this kind of services increases people's motivation to be referred to counseling service providers. Finally, it should be noted that, by receiving preventive health and treatment services, the risk of behavioral disorders will be reduced in the society (30). Designing a sexual health system was among the points emphasized by many participants. Integration of services using information technology to modernize health care network could improve the quality of medical services at the macro level (31). 


\section{Limitations}

Since the samples were collected only from the city of Rasht and also formation of sexual schemas within a population could be different, even from one city to another, the fact that results of this study are not generalizable, like other qualitative studies, was one of the limitations of this work. In qualitative studies, results largely depend on social and cultural background. Sampling with a maximum variation (diversity) in gender, age, education, and different socio-economic levels were among the strong points of this study.

\section{Conclusions}

The results of this research showed that sexual health promotion requires the application of public policies and special measures in the health system and that well-designed sexual health promotion programs can be effective in providing, maintaining, and improving individuals' sexual health. To achieving these goals, the current system of health services must be reviewed and appropriate changes must be made.

\section{Acknowledgments:}

This study was a part of dissertation for receiving the Ph.D. degree in Reproductive Health, and the study was supported by the Shahid Beheshti Medical Science University, Tehran, Iran, with grant number (No.SBMU2.REC.1394.130). The authors extend their thanks to all of the participants who kindly shared their experiences.

\section{Conflict of Interest:}

There is no conflict of interest to be declared.

\section{Authors' contributions:}

All authors contributed to this project and article equally. All authors read and approved the final manuscript.

\section{References:}

1) World Health Organization. Defining Sexual Health, Report of Technical Consultation on Sexual Health 2002. Geneva. 2006.

2) Lottes IL. Sexual rights: meanings, controversies, and sexual health promotion. J Sex Res. 2013; 50(3-4): 367-91. doi: 10.1080/00224499.2013.764380. PMID: 23480078.

3) Eisenberg ME, Bernat DH, Bearinger LH, Resnick MD. Support for comprehensive sexuality education: perspectives from parents of school-age youth. J Adolesc Health. 2008; 42(4): 352-9. doi: 10.1016/j.jadohealth.2007.09.019. PMID: 18346660.

4) Pan American Health Organization. Promoting sexual health: Recommendations for Action. Washington DC. 2000.

5) Javadnoori M, Roudsari RL, Hasanpour M, Hazavehei SM, Taghipour A. Female adolescents' experiences and perceptions regarding sexual health education in Iranian schools: A qualitative content analysis. Iran J Nurs Midwifery Res. 2012; 17(7): 539-46. PMID: 23922603, PMCID: PMC3730460.

6) Fenton KA. Strategies for improving sexual health in ethnic minorities. Curr Opin Infect Dis. 2001; 14(1): 63-9. PMID: 11979117.

7) World Health Organization. The Ottawa Charter for Health Promotion. 1986. Available from: http://www.who.int/healthpromotion/conferences/previous/ottawa/en/

8) Haberland N, Rogow D. Sexuality education: emerging trends in evidence and practice. J Adolesc Health. 2015; 56(1): 15-21. doi: 10.1016/j.jadohealth.2014.08.013.

9) Gold J, Lim MS, Hellard ME, Hocking JS, Keogh L. What's in a message? Delivering sexual health promotion to young people in Australia via text messaging. BMC Public Health. 2010; 10: 792. doi: 10.1186/1471-2458-10-792. PMID: 21190584, PMCID: PMC3022861.

10) Janghorban R, Latifnejad Roudsari R, Taghipour A, Abbasi M, Lottes I. The Shadow of Silence on the Sexual Rights of Married Iranian Women. Biomed Res Int. 2015; 2015: 520827. doi: 10.1155/2015/520827. PMID: 25705669, PMCID: PMC4331327.

11) Bostani Khalesi Z, Ghanbary Khanghah A. Perception and experience of married women of reproductive age about the importance of sexual health education: A content analysis study. IJOGI. 2015; 18(172): 7-17.

12) Latifnejad Roudsari R, Javadnoori M, Hasanpour M, Hazavehei SM, Taghipour A. Socio-cultural challenges to sexual health education for female adolescents in Iran. Iran J Reprod Med. 2013; 11(2): 10110. PMID: 24639734, PMCID: PMC3941358. 
13) DeJong J, Jawad R, Mortagy I, Shepard B. The sexual and reproductive health of young people in the Arab countries and Iran. Reprod Health Matters. 2005; 13: 49-59. doi: 10.1016/S0968-8080(05)25181-9. PMID: 16035597.

14) Moreira ED, Brock G, Glasser DB, Nicolosi A, Laumann EO, Paik A, et al. Help-seeking behavior for sexual problems: The global study of sexual attitudes and behaviors. Int J Clin Pract. 2005; 59: 6-16. doi: 10.1111/j.1742-1241.2005.00382. PMID: 15707457.

15) Graneheim UH, Lundman B. Qualitative content analysis in nursing research: Concepts, procedures and measures to achieve trustworthiness. Nurse Educ Today. 2004; 24(2): 105-12. doi: 10.1016/j.nedt.2003.10.001. PMID: 14769454.

16) Guba E, Lincoln Y. Fourth generation evaluation. Newbury Park, CA: Sage. 1999.

17) Kirby DB, Laris BA, Rolleri LA. Sex and HIV education programs: Their impact on sexual behaviors of young people throughout the world. J Adolesc Health. 2007; 40: 206-17. PMID: 17321420.

18) Harries J, Cooper D, Myer L, Bracken H, Zweigenthal V, Orner P. Policy maker and health care provider perspectives on reproductive decision-making amongst HIV-infected individuals in South Africa. BMC Public Health. 2007; 7: 282.

19) Gruber KJ, Jones RJ. Identifying determinants of risk of sexual victimization of youth. Child Abuse Negl. 1983; 7: 17-24. PMID: 6684973.

20) Sobhanifar MJ, Nouroozi Rouh E. From Cultural Aggression to Soft War and the Ways to Confront Them From the Viewpoints of the Supreme Leader. Journal of the Islamic Revolution Cultural Preservation. 2012; 2(5): 89-117.

21) Rogstad KE, Ahmed-Jushuf IH, Robinson AJ, MSSVD Adolescent Sexual Health Group. Standards for comprehensive sexual health services for young people under 25 years. Int J STD AIDS. 2002; 13(6): 4204. PMID: 12015018.

22) Merzel C, D’Afflitti J. Reconsidering Community-Based Health Promotion: $\neg \neg \neg$ Promise, Performance, and Potential. Am J Public Health. 2003; 93(4): 557-74. PMID: 12660197, PMCID: PMC1447790.

23) Jones JP, Andriamarovololona MM, Hockley N. The importance of taboos and social norms to conservation in Madagascar. Conserv Biol. 2008; 22(4): 976-86. doi: 10.1111/j.1523-1739.2008.00970. PMID: 18616743 .

24) Forsythe S, Arthur G, Ngatia G, Mutemi R, Odhiambo J, Gilks C. Assessing the cost and willingness to pay for voluntary HIV counselling and testing in Kenya. Health Policy Plan. 2002; 17(2): 187-95. PMID: 12000779.

25) Barnett DJ, Taylor HA, Hodge JG Jr, Links JM. Resource Allocation on the Frontlines of Public Health Preparedness and Response: Report of a Summit on Legal and Ethical Issues. Public Health Rep. 2009; 124(2): 295-303. PMID: 19320372, PMCID: PMC2646457.

26) Rothkopf J, Brookler K, Wadhwa S, Sajovetz M. Medicaid patients seen at federally qualified health centers use hospital services less than those seen by private providers. Health Aff (Millwood). 2011; 30(7): 1335-42. doi: 10.1377/hlthaff.2011.0066. PMID: 21734208.

27) Rahmanian F, Simbar M, Ramezankhani A, Zaeri F. The concept and dimensions of Gender sensitive STIs/HIV/AIDS prevention services: a qualitative study. Sjsph. 2014; 12(1): 29-40.

28) Rostamkhani F, Jafari F, Ozgoli G, Shakeri M. Addressing the sexual problems of Iranian women in a primary health care setting: A quasi-experimental study. Iran J Nurs Midwifery Res. 2015; 20(1): 139-46. PMID: 25709703, PMCID: PMC4325406.

29) Shahhosseini Z, Simbar M, Ramezankhani A. Female Adolescents Health-Information Needs: A Qualitative Study. J Mazand Univ Med Sci. 2011; 20(80): 81-5. doi: 10.1016/s0924-9338(11)72060-0.

30) Ranji UR, Wyn R, Salganicoff A, Yu H. Role of health insurance coverage in women's access to prescription medicines. Womens Health Issues. 2007; 17(6): 360-6. PMID: 18042485.

31) Peters DH, Mirchandani GG, Hansen PM. Strategies for engaging the private sector in sexual and reproductive health: how effective are they? Health Policy Plan. 2004; 19: 5-21. PMID: 15452011. 